in their true positions of passing near the several radiant-centres, but directed upwards and downwards alternately, for each radiant-point in turn, so as not very sensibly to confuse each other. The lines are also drawn of such lengths as to show by ending at different border-lines of the diagram, at what date, or approximate date (for the few Perseids' paths noted on July $20,23,25-6,28$, and 31 , and on August 4 and 6 are referred to the nearest special dates, by their line-lengths, only) in July or August any path-line was observed. In this way the progress of the radiation is either visible in its main outline at a glance, or any special peculiarities and features of it may be studied closely in detail.

It may thus be noted easily that although not dying out for some days longer, the activity of shower I. was chiefly confined to the first week (up to July 27) of the watch; while the meteors of shower II., first appearing only on July 30 , continued, with a maximum on August 2, to show themselves brightly up to August 3 ; and that little was to be seen of the main stream of $\eta$-Perseids (shower IV.) until August 2-3, when it was still inconspicuous, but when a precursor limb of it, the intermediate shower III., was about as active beside shower II. as it again became afterwards on August 8, but more feebly on August 9, beside the plentiful displays then going on, of the showers IV. and V. from $\eta$ Persei and B, C Camelopardi.

The offshoot as it seemed of the main shower's radiation, at the latter place, showed like the main stream itself, but slight signs of its existence, either in July or later, until August 6, when four of six meteors (all Perseïds), seen in an hour, diverged very distinctly from a point thus first well indicated near B, C Camelopardi. On the nights of August 8 and 9 it appeared to form an almost equally intense companion-shower to the $\eta$ Perseids; and as it seems to conform well in its position to the straight onward line of motion of the other Perseìd centrepoints, and to add apparently another link-step to the regular earlier stages of a chain-like progression, it might have been expected, had the nights of the IOth and I Ith of August not been such unfavourable ones for noting any further changes in these loci of divergence, that with the expiration of the $\eta$ Perseid shower IV., the accompanying stream V. from $\mathrm{B}, \mathrm{C}$ Camelopardi, would perhaps survive it, or else would on some later night reappear with a new and naturally much weaker maximum agreeirg with its theoretically proper apparition-date.

Some future years' clear skies, it may be hoped will allow the after-showers of Perseids, already very clearly and distinctly traced by $\mathrm{Mr}$. Denning, to be seen and noted in not less splendid weather than that which so well and continuously displayed the phases of the preceding showers' appearances in the present year.

Several exceptionally bright meteors; and some smaller ones presenting specially remarkable features of appearance, were noted in my watch, which, together with the real paths obtained from corresponding observations at other places of some of the shooting-stars and fireballs of its list, would furnish me with a sufficient abundance of interesting notes to fill another letter. But the subject of the latter meteors will be discussed more satisfactorily and completely in a general review of the collected observations which Mr. Denning and Mr. Corder are conducting; and satisfactory descriptions of the former meteors would involve more searches among known radiant-points, with full deductions of their radiant-centres for the 167 sporadic meteors of my list, than I have yet attempted, to summarise correctly the points of leading and rather novel interest which were presented by the radiations of some of the more particularly striking meteors. I must forego, therefore, a review of features of interest, and of real path conclusions which some of the individual meteors offered very attractively for description, although I felt at first much prompted to describe them; in order to place their discussion in the hands of those much better and more strely able than myself to judge of their importance, who in combination with Mr. Denning undertook the arduous task of collecting and the necessarily much slower and more dilatory task of abstracting and collating all these numerous descriptions.

Observatory House, Slough, September 21.

A Colony of Highly Phosphorescent Earth-Worms.

In the sheltered westward corner of a small grass-plat in this city there is a colony of highly phosphorescent earth-worms. The annelid is round, pellucid, slender, of a faint yellowish tint, is about two inches long, and is not flattened behind. I have been unable to distinguish segmentation. The worm is entirely luminous. The phosphorescence has precisely the bright greenish colour of the light emitted by the glow-worm. The light is under control. When in glow its secretion is luminous, as is seen in its trail and in the phosphorescence imparted to the hands when handled. It is said by the owner of the grassplat that the casts are luminous. This is a point $I$ have had no opportunity of observing.

At night the slightest irritation suffices for lighting-up. I captured one in a small clod of turf, to transplant in my grassplat. The very slightest pressure of the clod, which I should have thought inappreciable, brought on a manifestation of light. On nights when not on the crawl and not otherwise visible, a favourite expedient is to stamp on the ground to get them to come to the surface. The worms in response at once rise to the surface and light up, as though it were possible for them to show fight, instead of, like other worms, scampering away.

The spot colonised is far from humid, but the worms are more active in wet than in dry weather. The worm is new to this place, and, as far as my researches go, it has not been observed west ward in Wales. It seems to me to be an instance of Lumbricus phosphoreus, but it hardly agrees with the published description of that organism. I want to avoid depleting the colony, or putting any of the inmates to torture, but I could at least furnish a specimen.

Worcester, September 27

J. LLOYD-BOZWARD.

\section{Appearance of a Noddy in Cheshire.}

THE other day, when looking through a collection of stuffed birds, I saw and obtained a specimen of the Neddy Tern (Stema stolida, Linn.). It is in immature plumage, the white on the crown being only just visible.

It was shot on the Dee marshes in winter about six years ago.

As I believe this Tern has been only twice recorded as visiting Europe, I think this specimen worth mention.

Neston, Cheshire, September 29.

F. Congreve.

\section{THE ETNA OBSERVATORY.}

A RECENT number of La Nature (No. 1262) conA tains an interesting illustrated account of the observatory on Mount Etna, a building which was originally designed by Prof. Tacchini for some special investigations which he had in hand. The eruption which occurred in 1886 caused much disaster, and considerably affected the building which was not restored till the year 1891 . In the observatory at the present time there is an equatorial of 5.5 metres focal length, besides various meteorological and seismographical instruments. Observations are made regularly, except in the winter months. This year a very important addition will be made by the setting up of telegraph and telephone wires as far as Nicolosi, thus rendering it possible to regulate the work.

The ascent from Catania, which town lies at a distance of about 30 kilometres in a southerly direction, is made by coach as far as Nicolosi (700 metres). One proceeds then by mule as far as Casa del Bosco (I $440 \mathrm{~m}$.), and to the Alpine meteorological station ( $1890 \mathrm{~m}$.); this latter place being half-way between Nicolosi and the observatory. The rest of the way is made by foot over the snow ; the path, which is very rough, can be ascended by mule in the summer, but it is impossible in the winter, owing to the great accumulation of snow. The observatory is sometimes buried in the snow to a depth of two to five metres, admission being then only possible through the first-floor windows.

The disadvantages of Mount Etna as an observing station are therefore due more to the snow than to volcanic disturbances. Long periods elapse between the volcanic outbreaks, during which time the surface near the central crater and the observatory is quiet, so that even the most sensitive seismograph may be used.

$$
\text { NO. } 1458 \text {, VOL. 56] }
$$


When the outbreaks do occur they are usually very severe, and streams of lava pour down the sides of the mountain, devastating forests, vineyards and fields. Huge boulders, sometimes a cubic yard in volume, are also thrown up.

\begin{tabular}{lccccc} 
& & & \multicolumn{3}{c}{ Mean temperature. } \\
Winter & $\ldots$ & $\ldots$ & $\ldots$ & $\ldots$ & $-6^{\circ} \cdot 6$ \\
Spring & $\ldots$ & $\ldots$ & $\ldots$ & $\ldots$ & $-1^{\circ} \cdot 5$ \\
Summer & $\ldots$ & $\ldots$ & $\ldots$ &.. & $+7^{\circ} \cdot 3$ \\
Autumn & $\ldots$ & $\ldots$ &.. & $\ldots$ & $+2^{\circ} \cdot 7$ \\
The year & $\ldots$ & $\ldots$ & $\ldots$ & $\ldots$ & $+0^{\circ} \cdot 4$
\end{tabular}

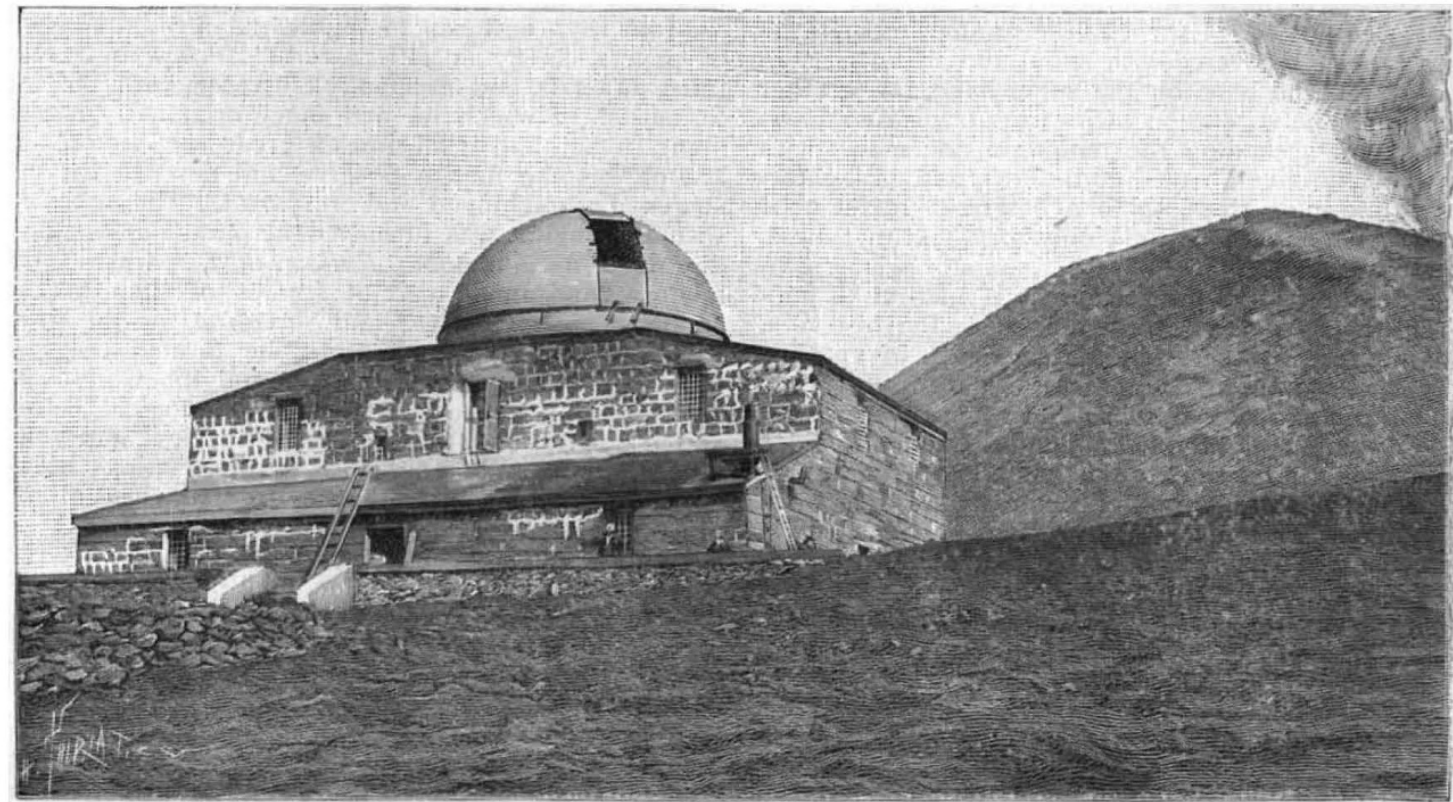

FIG. x.-The Etna Observatory.

The position of the observatory is as follows :

Altitude $\quad \ldots \quad \ldots \quad \ldots \quad 2942$ metres.

$\begin{array}{lllll}\text { Latitude } & \ldots & \cdots & \cdots & 37^{\circ} 44^{\prime} \cdot 3\end{array}$

Longitude (East) $\quad \ldots . \quad \ldots . \quad 2^{\circ} 33^{\prime} \cdot 8$ (Rome).
The temperature at the summit ought to be $2^{\circ} \cdot 2$ lower than that at the observatory, but observations have shown that it is $0^{\circ} 6$ greater, owing doubtless to the heat of the crater.

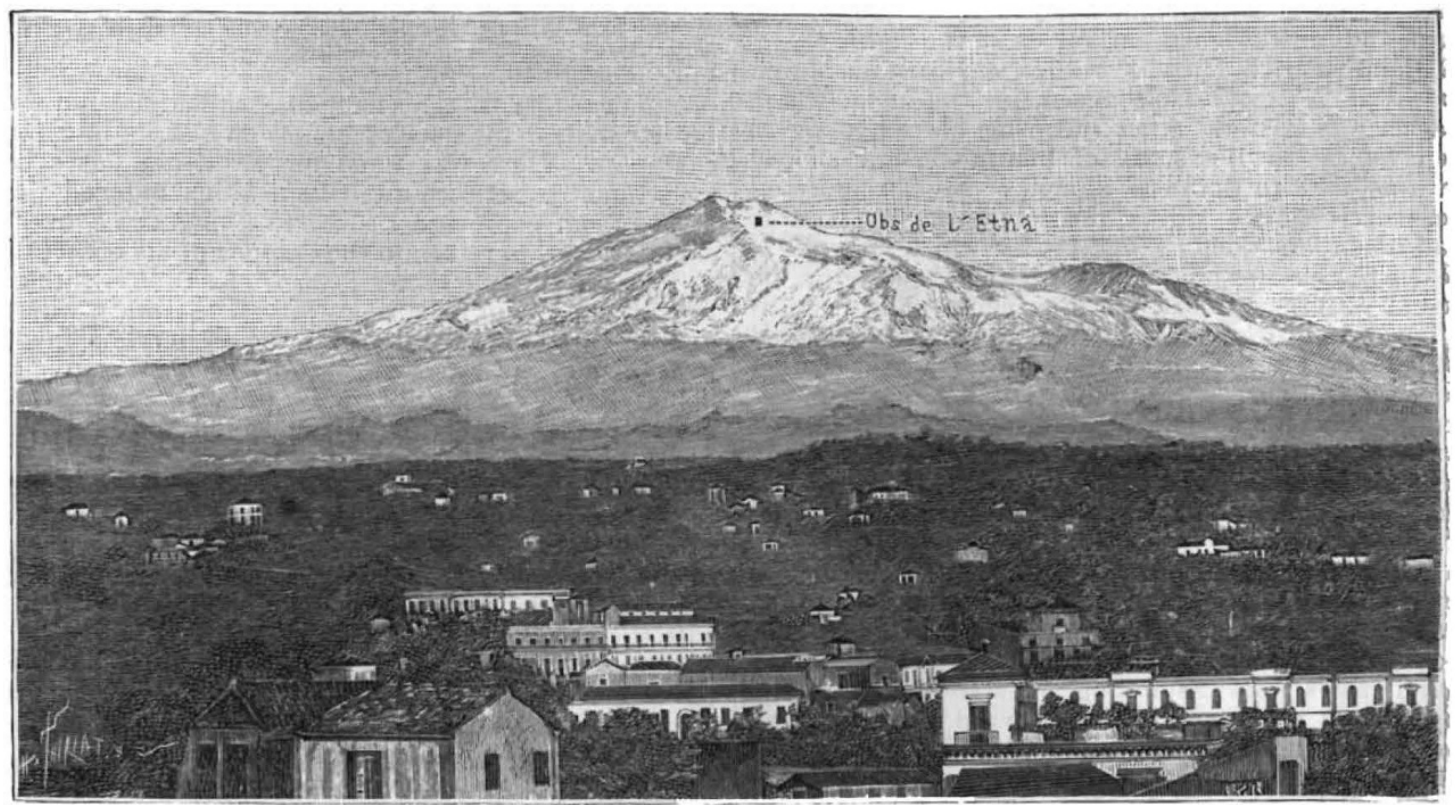

FIG. 2.-Showing the front of the Observatory near the summit of the mountain

It is situated one kilometre from the central crater, and on the southern side (Figs. I and 2). Meteorological observations made since 1892 have given the following mean results :-
Thunderstorms on Mount Etna are not common, and occur chiefly in the autumn. There is no lightning conductor fixed on the observatory, and up to the present time the latter has never been struck, although the large. 
metallic dome is not in any way connected metallically with the ground. The rareness of thunderstorms is accounted for by the presence of the central crater, the smoke and hot vapour of which act as a lightning conductor on a large scale.

The climate in the neighbourhood of the mountain is of a very varied nature. Except in the summer months the summit is always covered with snow, and it is therefore very cold. At the base, on the other hand, the weather is warm, and the vegetation varies from tropical to arctic species. On ascending the mountain one meets with cacti, oranges, olives, vines, corn, ferns, astragal, chestnut trees and pine trees, up to a height of about 2000 metres. At a higher altitude only rock, volcanic sand, and snow are found.

After an outbreak of the volcano it is natural to suppose that the snow is generally melted by the hot lava. It is of interest, however, to note that a layer of volcanic cinders has been known to protect the snow from lava at a temperature of about $1000^{\circ}$, so that when covered by it the snow was but slightly melted, and the lava formed a black covering in contrast to this white background.

The view from the summit of Mount Etna is described as most magnificent, extending nearly 200 kilometres in all directions. This is due to the fact that the air at this height is reduced to a third of its density, and is of extreme transparency.

\section{FRITZ MÜLLER.}

THE death of Dr. Fritz Müller, which took place on May $2 \mathrm{I}$ at Blumenau, in South Brazil, has inflicted upon science a loss, the importance of which needs no pointing out. Although the greater part of his life was passed at a distance from the centres of scientific thought, and his ratural modesty and self-effacement left him indifferent to his own fame, it has long been recognised that the qualities of observation and interpretation which drew from Darwin the title of "the prince of observers," have earned him a position as one of the greatest and most original naturalists of the century.

Johann Friedrich Theodor Müller was born on March 3I, I822, at Windisch-Holzhausen, in Thuringia, where his father was pastor. After receiving his schooling at Erfurt, he began the study of pharmacy, but shortly afterwards went to Berlin as a pupil of his distinguished namesake, Johannes Müller, the zoologist. As soon as he had taken his doctor's degree, for which he wrote a thesis on the leeches of the neighbourhood of Berlin, he settled at Erfurt as a teacher of science. The occupation, however, proved uncongenial, and he again changed his studies, and turned to medicine, with a view to becoming a ship's surgeon, and thus gaining opportunities for travel and for zoological work in foreign countries. During this early period he began gradually to make a name for himself in science by the occasional publication of various morphological and descriptive papers on leeches and crustacea.

In 1852 the liberal character of his political views brought about a crisis which led to his leaving Germany and betaking himself to Blumenau, on the river Itajahy, just outside the limits of the tropics, where, his education and tastes notwithstanding, he settled down to the occupation of a farmer. Henceforward Brazil was his home, and to this fact and the freedom it brought from the limits set to observation by travel and temporary residence is largely due his distinctive position among naturalists. Under less fayourable conditions much of his work, particularly on morphological subjects and on matters involving experiment such as the hybridisation of plants, must have been impracticable. Nevertheless, his expatriation put an end to researcl for some years, until an appointment as teacher of mathematics at the No. I $45^{8}$, VOL 56$]$ gymnasium of Desterro, on the island of Sta. Catharina, gave him the wished-for opportunity, and he began assiduously to study the invertebrates of the Brazilian coast, and to overcome the difficulties which the absence of a properly-equipped zoological station and his remoteness from literature and fellow-workers entailed.

From 1857 onwards he published a rapid succession of papers, chiefly in Wiegmann's Archiv, on colenterates, annelids, and especially crustacea, with the transformations of which he was much occupied. Development, in fact, had at all times a great attraction for him, and he was the first to observe and describe the larval stages of a brachiopod and of Squilla. The material for several memoirs was furnished by parasitic forms. $\mathrm{He}$ described an anemone, Philomedusa, parasitic on a medusa, and made careful studies of such degraded crustacea as Entoniscus and Sacculina, for the latter of which, together with its allies, he formed the family Rhizocephalidæ. During this period his work was almost entirely concerned with morphological subjects, and it was not until the "Origin of Species" had brought a new interest and significance to the relations between structure and bionomics that he devoted close attention to field observation.

He must have become acquainted with the "Origin" very soon after its publication, and probably received a copy of it from his younger brother and devoted correspondent, Hermann Müller of Lippstadt. His initial attitude towards the book appears to have been critical rather than receptive, for he admits that it was an observation of his own wbich gave him the first decided imipulse in its favour. But he was not long in finding that he could unreservedly acrept its principles and devote his energies to their support; and the theory of natural selection gave a definite direction to the whole of his subsequent work.

The observation which determined his adherence to the theory of evolution was the discovery of the naupliuslarva of Pencus, a genus of prawns. Important as it is from its bearing on the phylogeny of the crustacea, in which malacostracous nauplius was previously unknown, and its influence on Müller himself, it has not even yet been fully confirmed. Müller succeeded in breeding the protozoæa-stage from his nauplius, but had to build up the further steps in the development from a series of captured examples. Here was room for error, and his account consequently met with a criticism which induced him, in spite of an expressed dislike to going twice over the same ground, to return to the defence of his observations in 1878 . Four years later Prof. W. K. Brooks succeeded in rearing Pencus from a protozoæa, "identical with that developed by Fritz Müller," but the assumption involved in this statement was such as to prevent the matter from being regarded as settled, and Müller's account, though presumptively correct, is still accepted with reserve by some carcinologists.

The philosophic bent of his mind soon led Muiller to recognise the possibility of testing the principles of evolution by applying them towards the building-up of the phylogeny of some group of animals, and ascertaining how far the theoretical results obtained were reconcilable with the observed facts of development. The idea was put into practice for the crustacea in a little book published in I 865 , the well-known "Für Darwin," which had a great success in spite of its technical character and limited scope. This success was probably due not merely to the value of its accounts of crustacean development, which embody the main results of Müller's own researches, and the then novel support which the deductive argument brought to evolution, but also to the brilliant simplicity of a title which disclosed nothing beyond the fact of his advocacy and would have served even better to cover the whole of his subsequent writings. At that time the principle of evolution itself was at stake, 